\title{
Preliminary Neutronic Design of High Burnup OTTO Cycle Pebble Bed Reactor
}

\author{
T. Setiadipura ${ }^{1^{*}}$, D. Irwanto ${ }^{2}$ and Zuhair $^{1}$ \\ ${ }^{I}$ Center forNuclear Reactor Technology and Safety, National Nuclear Energy Agency, \\ Puspiptek Area, Serpong Tangerang 15310, Indonesia \\ ${ }^{2}$ Nuclear Physics and Biophysics Research Group, Pyshics Dept., Bandung Institute of Technology \\ Jl. Ganesha 10, Bandung 40132, Indonesia
}

\section{ARTICLE INFO}

\section{Article history:}

Received 04 October 2014

Received in revised form 26 February 2015 Accepted 27 February 2015

\section{Keywords:}

High temperature gas-cooled reactor

Pebble bed reactor

Once-through-then-out cycle

High burnup

\begin{abstract}
A B S T R A C T
The pebble bed type High Temperature Gas-cooled Reactor (HTGR) is among the interesting nuclear reactor designs in terms of safety and flexibility for cogeneration applications. In addition, the strong inherent safety characteristics of the pebble bed reactor (PBR) which is based on natural mechanisms improve the simplicity of the PBR design, in particular for the Once-Through-Then-Out (OTTO) cycle PBR design. One of the important challenges of the OTTO cycle PBR design, and nuclear reactor design in general, is improving the nuclear fuel utilization which is shown by attaining a higher burnup value. This study performed a preliminary neutronic design study of a $200 \mathrm{MWt}$ OTTO cycle PBR with high burnup while fulfilling the safety criteria of the PBR design.The safety criteria of the design was represented by the per-fuel-pebble maximum power generation of $4.5 \mathrm{~kW} /$ pebble. The maximum burnup value was also limited by the tested maximum burnup value which maintained the integrity of the pebble fuel. Parametric surveys were performed to obtain the optimized parameters used in this study, which are the fuel enrichment, per-pebble heavy metal (HM) loading, and the average axial speed of the fuel. An optimum design with burnup value of $131.1 \mathrm{MWd} / \mathrm{Kg}-\mathrm{HM}$ was achieved in this study which is much higher compare to the burnup of the reference design HTR-MODUL and a previously proposed OTTO-cycle PBR design. This optimum design uses 17\% U-235 enrichment with $4 \mathrm{~g}$ HM-loading per fuel pebble.
\end{abstract}

(C) 2015 Atom Indonesia. All rights reserved

\section{INTRODUCTION}

The pebble bed type high temperature gascooled reactor (HTGR) is an interesting nuclear reactor design which offers improved safety and flexibility for co-generation applications. With the helium $(\mathrm{He})$ gas output from its core, the pebble-bed reactor (PBR) is a very attractive potential solution to the electricity and heat demands in Indonesia, a country with a very large population and vast natural resources. Small PBR design are highly appropriate with the small and distributed energy (electricity and / or heat) demands in Indonesia. In addition, the PBR core design is simplified since its strong inherent safety characteristics are based on natural mechanisms. Further, its relatively low

\footnotetext{
* Corresponding author.

E-mail address:tsdipura@batan.go.id

DOI: http://dx.doi.org/10.17146/aij.2015.350
}

susceptibility to damages from earthquakes improves the safety aspect of the PBR's potential use in Indonesia [1]. Studies on the PBR design and their applications, including the development of tools for the design analysis of PBR, have been performed in Indonesia [2]. Recent works on the PBR designs show a reviving interest in PBR application in Indonesia, in particular the OTTO (once through then out)-cycle PBR, for its simplicity and superior high temperature potential. The core power of $200 \mathrm{MWt}$ was considered to be suitable for the Indonesian demands [3,4].

The three most common fuel loading cycles in a PBR are the multi-pass, once-through-then-out (OTTO), and peu-a-peu (PAP) cycles. In the PAP cycle, the reactor core starts with its lower layer partially filled with fuel pebbles, leading to the first criticality. Then, at various time intervals, 
one fuel layer after another is added to maintain the criticality of the core. In the multi-pass fueling cycle, fuel pebbles are inserted from the top, pass through the core, and are unloaded from the bottom. Then the burnup of each unloaded pebble is measured, and the pebble is reloaded to the top of the core until its burnup reaches the targeted burnup. An OTTO cycle PBR differs from conventional multi-pass cycle PBRs in that each pebble only passes the core once. Hence, burnup measurement and fuel reloading devices become unnecessary. The OTTO cycle PBR is chosen in this study due to its simplicity and its better potential for high temperature heat production for co-generation [5].

The main purpose of this research is to perform a preliminary neutronic design study of a 200 MWt OTTO cycle PBR with high burnup and high utilization of fissile material; this is important because the amount of available fissile materials is limited. Research activities have been conducted on improving the utilization of fissile materials in pebble-bed reactors by adding burnable poisons [6] or combining the thorium-based fuel [7]. Comparison between the OTTO cycle and the reference multi-passes cycle shows that their core performances are comparable but the fuel burnup of the OTTO cycle is about $21-22 \%$ lower than that of the multi-passes cycle [8]. The burnup of the previously proposed OTTO cycle is $80 \mathrm{MWd} / \mathrm{kg}$ of heavy metal (HM) loading [9]. Considering the advantages offered by the OTTO cycle, it is becoming more important to increase its burnup performance while maintaining the safety characteristics. In this study, the burnup performances will be optimized based on $\mathrm{UO}_{2}$ fuel without using additional burnable poisons or thorium fuel. Parametric surveys will be performed to obtain the optimized values of fuel enrichment, per-pebble heavy metal loading, and average axial speed of the fuel so that an optimized PBR design with high burnup could be achieved. This study can contribute to the current initiative on the PBR design in Indonesia, particularly in the equilibrium core neutronic design and its optimization.

\section{DESIGN PRINCIPLES}

Basically, the present design study uses the HTR-MODUL [10] as the reference design. However, unlike the HTR-MODUL design, which uses the multi-pass cycle, the present study uses the OTTO cycle design. Reactor design parameters, including optimized parameters, are given in Table 1.

The present design employs the standard pebble fuel design, which is based on tristructural-isotopic (TRISO) coated particles as illustrated in Fig. 1. This fuel design assures a sound fission product retention capability, resulting in low release of radioactive material to the environment in any condition of the core including the most severe postulated accident. The presence of graphite reflector which also functions as the core structure, in addition to the significant content of graphite in the fuel, improves the thermal characteristics of the core due to the high heat conductivity and capacity of graphite. Neutronically, significant graphite material compositions in the reactor improve the thermal neutron spectrum of the core due to its effective neutron thermalization capability. An inert $\mathrm{He}$ gas coolant avoids any chemical or physical reactions which might disrupt the neutron economy of the core.

Table 1. Reactor design parameters.

\begin{tabular}{|c|c|c|}
\hline Parameter & Unit & Value \\
\hline \multicolumn{3}{|l|}{ Core } \\
\hline Power & MWt & 200 \\
\hline Diameter / Height & $\mathrm{cm}$ & $300 / 480$ \\
\hline $\begin{array}{l}\text { Height of void (above the } \\
\text { active core) }\end{array}$ & $\mathrm{cm}$ & 40 \\
\hline $\begin{array}{l}\text { Max. per-pebble power } \\
\text { generation }\end{array}$ & $\mathrm{kW} /$ pebble & 4.5 \\
\hline U-235 enrichment & $\%$ & optimized in this study \\
\hline Per-pebble HM-loading & $\mathrm{g}$ & optimized in this study \\
\hline Average of axial fuel speed & $\mathrm{cm} /$ day & optimized in this study \\
\hline Average burnup & $\begin{array}{l}\mathrm{MWd} / \mathrm{Kg}- \\
\mathrm{HM}\end{array}$ & optimized in this study \\
\hline \multicolumn{3}{|l|}{ Fuel pebble } \\
\hline Diameter & $\mathrm{cm}$ & 6 \\
\hline $\begin{array}{l}\text { Thickness of outside graphite } \\
\text { shell }\end{array}$ & $\mathrm{cm}$ & 0.5 \\
\hline \multicolumn{3}{|l|}{ TRISO coated fuel particle } \\
\hline $\mathrm{UO}_{2}$ Kernel radius & $\mathrm{cm}$ & 0.025 \\
\hline Density of $\mathrm{UO}_{2}$ Kernel & $\mathrm{Kg} / \mathrm{m}^{3}$ & 10.4 \\
\hline Coating type (inside - out) & & buffer/I-PyC/SiC/OPyC \\
\hline Thicknes of each coating & $\mathrm{cm}$ & $0.009 / 0.004 / 0.0035 / 0.004$ \\
\hline Density of each coating & $\mathrm{g} / \mathrm{cm}^{3}$ & $1.05 / 1.9 / 3.19 / 1.9$ \\
\hline
\end{tabular}




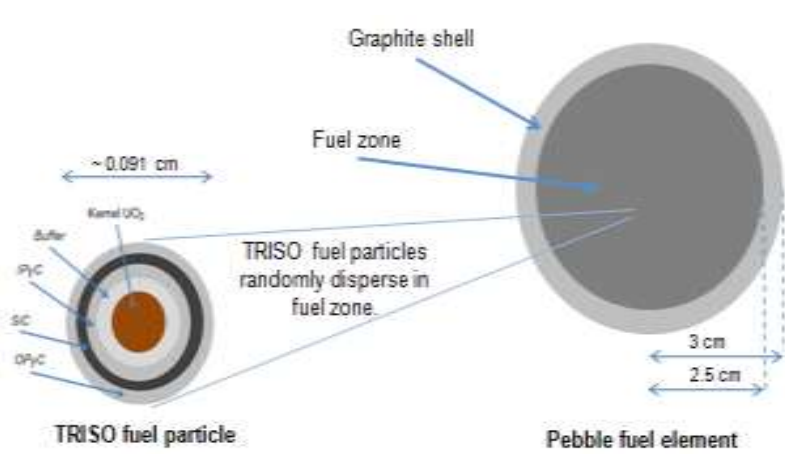

Fig. 1. Illustration of the pebble fuel elemen and TRISO fuel particle used in the Pebble Bed Reactor design.

A small diameter core concept is applied in this design. The diameter of the core is $3 \mathrm{~m}$ to allow the control rod only in the radial reflector without penetrating the core, and to keep the thermal capability to transfer heat from the core by natural mechanisms only, which gives the core its inherent safety.

The height of the core is $4.8 \mathrm{~m}$ to fulfill the criterion given by Teuchert et al. [9] that the OTTO-cycle PBR core should be less than $5 \mathrm{~m}$ in height. This condition will avoid the Xenon (Xe) oscillation by allowing sufficient transfer of neutrons from the top part of the core, which contains fresh fuel pebbles, to the bottom part containing older fuel pebbles.

The design also employs a very low power density, as low as $5.8 \mathrm{~W} / \mathrm{cm}^{3}$. Although this power density is higher than the $3 \mathrm{~W} / \mathrm{cm}^{3}$ of the HTR-MODUL design, it is still only about $1 / 20$ of a light water reactor's power density. This means that the amount of energy and heat produced inside the reactor is volumetrically low so that in an extreme accident condition with no forced cooling system available, natural mechanisms such as conductive and radiative heat transfers are sufficient to remove the remaining heat so that no fuel damages and meltdown occur [11].

In a moving-core PBR (multi-pass and OTTO-cycle PBR), the lifetime of the core can be divided into several phases. Initially, with certain condition the core will achieve its first criticality. By adding more fuel pebbles the core will have the initial core with full power; then, as the fuel loading continues the core will have a start-up or running-in phase in which the neutron flux, power density profile, and the effective multiplication factor $\left(\mathrm{k}_{\text {eff }}\right)$ are still changing. Finally, the core will achieve the equilibrium condition which will last for the lifetime of the core. The phases prior to the equilibrium phase are sometime jointly called pre-equilibrium phase. The core performance of the PBR design is usually represented by the performance of the core at the equilibrium, hence equilibrium calculation is important and practically the first phase in designing the PBR core[12].

A parametric survey of the uranium enrichment, per-pebble heavy-metal (HM) loading, and axial fuel speed was performed in this study to achieve a higher burnup compared to the HTRMODUL design which attained an average burnup of $80 \mathrm{GWd} / \mathrm{t}-\mathrm{HM}$. The fuel pebbles are able to withstand a burnup up to $150 \mathrm{MWd} / \mathrm{Kg}-\mathrm{HM}$ [5]; therefore, it is desirable to design a PBR which utilizes fuels more effectively as shown by a much higher burnup value. A nuclear reactor design with a high fuel utilization is important to support the sustainability of nuclear reactor application in terms of cost and fuel supply. The HTR-MODUL design uses a $7.8 \%$ U-235 enrichment and a 7 g HMloading, while in the present study the parametric survey of uranium enrichment exploited the 20\% maximum limit for nuclear grade utilizations. The analysis to quantify the effect of using higher enrichment, e.g. to the overall cost of the design, is beyond this optimization study.

To keep sound inherent safety characteristics, the integrity of the pebble fuel is one of the main safety criteria of the PBR designs. Therefore, the safety criteria used in the current study is the maximum power generation per fuel pebble which will keep the integrity of the fuel pebble. In the present design study, a maximum power generation of $4.5 \mathrm{~kW} /$ pebble is applied as the safety criterion [2]. The detail design of the control rods and the dynamic parameters of the core to assure the shutdown capability of the core are beyond the scope of the present study. However, adding to the previous design criteria, it is desirable that the equilibrium $\mathrm{k}_{\text {eff }}$ is kept as low as possible.

Improving the burnup value under the limit of certain maximum power density while keeping the desired core power of $200 \mathrm{MWt}$ and reducing the core height following OTTO cycle criteria[9] is a challenge to be overcome in this study.

\section{CALCULATIONAL METHODS}

As the PBR considered is a moving-core reactor, the burnup analysis of the PBR should also consider the axial movement of the pebble ball. The burnup equation to be solved in analyzing this reactor is given in Eq.1 [12]: 


$$
\begin{aligned}
& \frac{\partial \mathrm{N}_{\mathrm{k}}}{\partial \mathrm{t}}+\frac{\partial \mathrm{N}_{\mathrm{k}}}{\partial \mathrm{z}} v=\phi \sum_{\mathrm{i}=\mathrm{l}}^{\mathrm{m}} \mathrm{N}_{\mathrm{i}} \sigma_{\mathrm{fi}} \mathrm{y}_{\mathrm{ik}}+\phi \sum_{\mathrm{s}=\mathrm{r}}^{\mathrm{q}} \mathrm{N}_{\mathrm{s}} \sigma_{\mathrm{as}} \gamma_{\mathrm{sk}}+ \\
& \sum_{\mathrm{j}=\mathrm{n}}^{\mathrm{p}} \mathrm{N}_{\mathrm{j}} \lambda_{\mathrm{j}} \alpha_{\mathrm{jk}}-\lambda_{\mathrm{k}} \mathrm{N}_{\mathrm{k}}-\phi \mathrm{N}_{\mathrm{k}} \sigma_{\mathrm{ak}}
\end{aligned}
$$

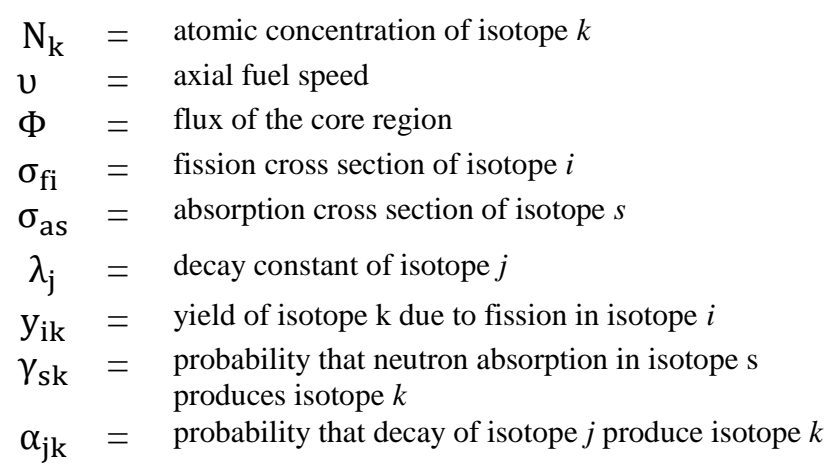

The summation indices $i, s$, and $j$ extend to all fissionable isotopes, isotopes which produce isotope $k$ by absorption reaction, and isotopes whose decay product can be isotope $k$, respectively .

The strategy to perform the burnup analysis of PBR used in this research is by coupling a neutron transport analysis, including burnup analysis, and additional simulation to move the fuel following the OTTO cycle fuel movement. The neutron transport and burnup analysis was performed using a continuousenergy Monte Carlo code called MVP-BURN [13]. Methods to model the double heterogeneity of PBRs have been developed recently for various Monte Carlo-based codes [14-16]. However, the intrinsic statistical geometry model in the MVP-BURN code is appropriate to model the double heterogeneity and the stochastic nature of PBR core and fuel design correctly in a simple way. The Monte Carlo method which is applied in this study is preferable to have a more accurate neutronic calculation compared to the standard diffusion approximation [17]. Several studies on the PBR design also used MVP-BURN as the main calculation tools $[6,8,18]$.

The calculation and coupling method used in this study is the same as the method applied in MCPBR code [12]. The heavy metal burnup chain used in this calculation, as shown in Fig. 2, consists of 28 heavy nuclides from Th-232 up to $\mathrm{Cm}-246$ [13]. This burnup chain is able to accommodate the uranium and thorium fuel cycles, although the present study was limited to the uranium cycle. JENDL-4.0 [19], the latest nuclear data library from Japanese Atomic Energy Agency (JAEA), was used in this study.

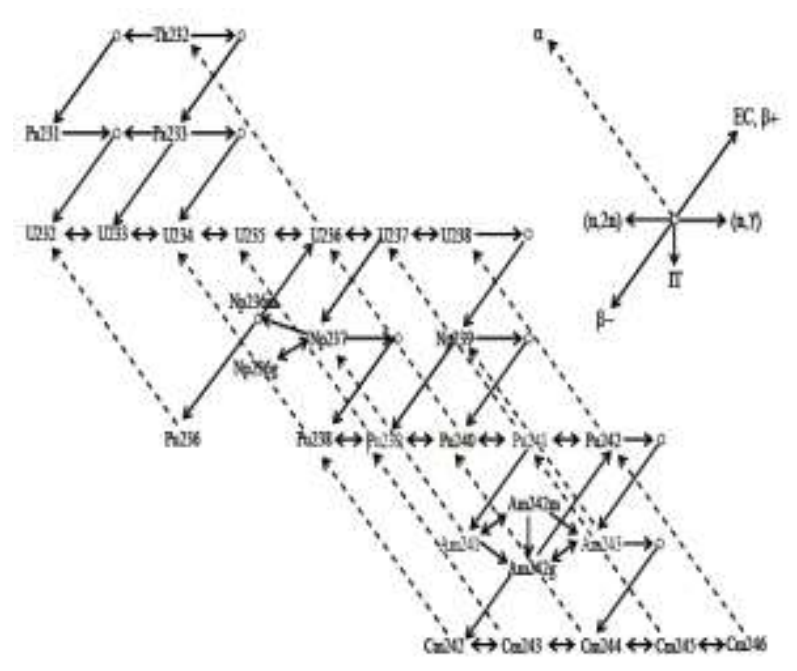

Fig. 2. Heavy Nuclide Chain used in the burnup calculation [21].

Geometrically, the cone shape at the bottom of the PBR core is omitted in the current calculation model. The core is modeled as cylindrical r-z geometry as shown in Fig. 3. The geometrical model is divided into 20 regions in the axial direction and 5 regions in the radial direction. This region mesh dimension is chosen by considering the needed calculation accuracy and the computational time [12]. This model is acceptable, in particular for preliminary design study, due to the low neutron flux at the bottom of the core as also performed in other PBR core analysis $[6,8]$.

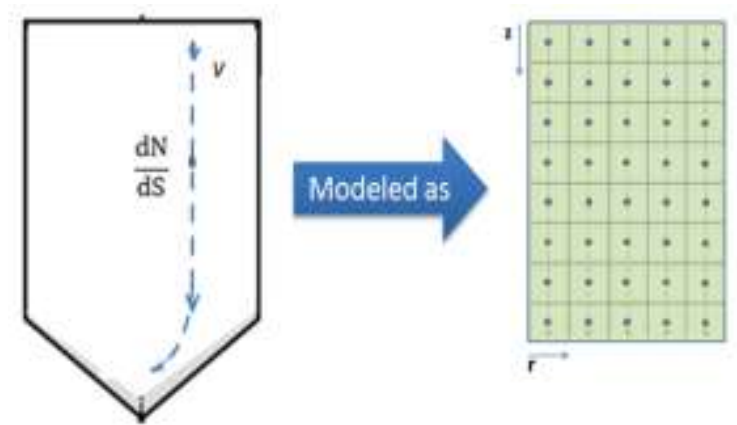

Fig. 3. Cylindrical r-z geometry used in the calculation to model the PBR core. In the figure, $d N / d S$ is the change of the nuclide density along the fuel pebble path [20].

The method which is applied in this calculation is able to simulate all the phases of the whole lifetime of PBR core including the preequilibrium and equilibrium phases. Hence, the method can be used for performing the optimization of both the equilibrium and the pre-equilibrium conditions. In this research, the calculation starts with the core fully loaded with a specific reactor design (fuel composition and average axial fuel speed). This initial core model is chosen due to its robustness in which the pre-burnup calculations which include pebble fuels with different 
burnup values to fill the initial core are not needed. Then, as the fresh fuel pebbles are continually loaded from the core top and the lowest-positioned pebbles are discharged from the core bottom following the OTTO cycle procedure, the core will enter the running-in period, which is shown by the changing of $k_{\text {eff }}$ and other parameters, and finally reach the equilibrium condition.

\section{RESULTS AND DISCUSSION}

The transition of $k_{\text {eff }}$ from the initial core up to the equilibrium core in the equilibrium analysis for different U-235 enrichment, HM-loading, and average axial fuel speed are given in Figs. 4-7. In those figures, as expected, the initial $\mathrm{k}_{\mathrm{eff}}$ values are the same for all designs with same parameters except the average axial fuel speed. The initial $k_{\text {eff }}$ values given in those figures are too high for a practical PBR core design. These results are due to the computational method used in this study, in which the initial core was simply loaded with homogeneous fresh fuels. Practically, the initial core can be loaded according to many different loading strategies involving dummy graphite pebbles which will give different initial and running-in phase conditions. The tools and method used in this study are capable of performing analyses of any initial core loading; however, the present study was focused on the performance of the equilibrium condition.

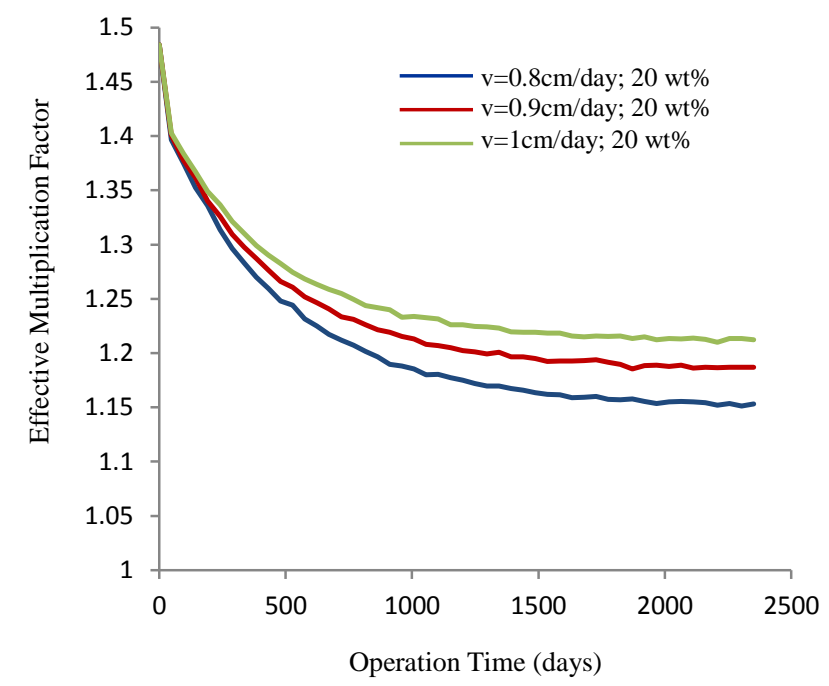

Fig. 4. Transition of effective multiplication factors from initial core to equilibrium core for $20 \% \mathrm{U}-235$ enrichment and $5 \mathrm{~g}$ $\mathrm{HM} /$ pebble.

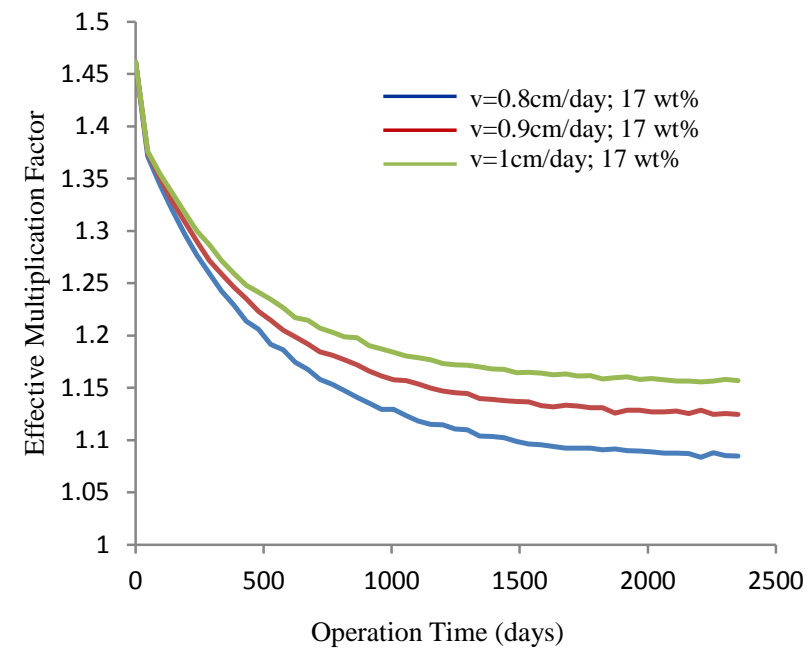

Fig. 5. Transition of effective multiplication factors from initial core to equilibrium core for $17 \% \mathrm{U}-235$ enrichment and $5 \mathrm{~g}$ $\mathrm{HM} /$ pebble.

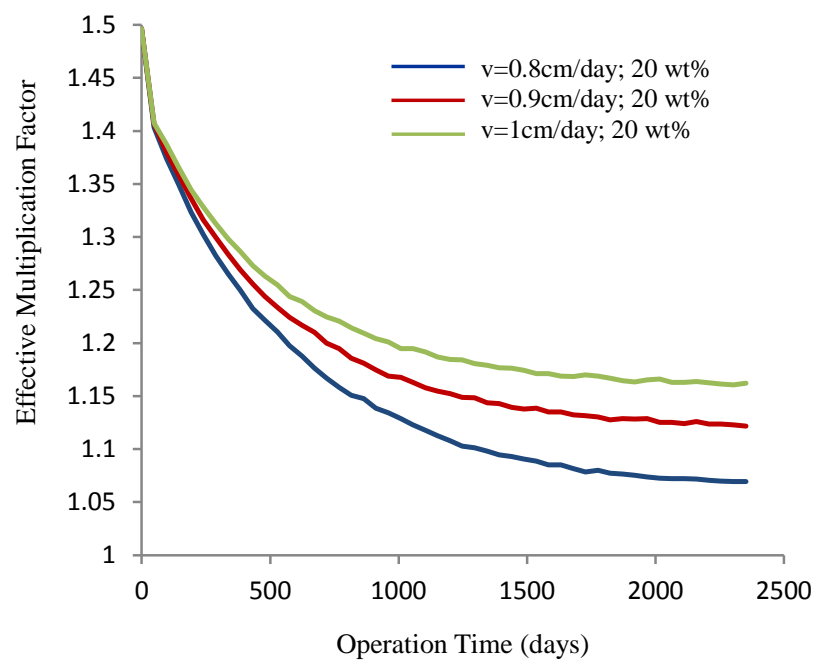

Fig. 6. Transition of effective multiplication factors from initial core to equilibrium core for $20 \% \mathrm{U}-235$ enrichment and $4 \mathrm{~g}$ $\mathrm{HM} /$ pebble.

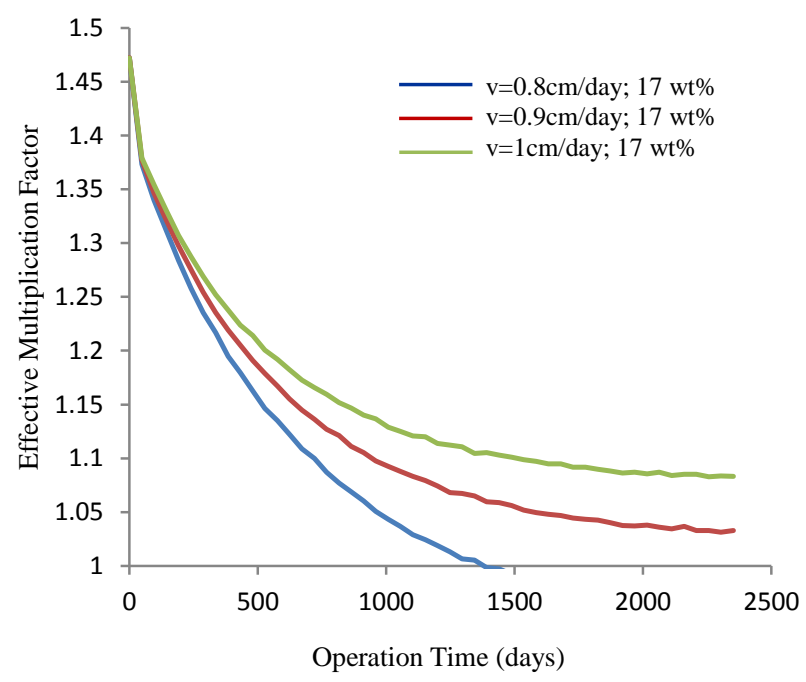

Fig. 7. Transition of effective multiplication factors from initial core to equilibrium core for $17 \% \mathrm{U}-235$ enrichment and $4 \mathrm{~g}$ $\mathrm{HM} /$ pebble. 
For the equilibrium condition, different average axial fuel speeds affect the equilibrium $\mathrm{k}_{\text {eff }}$. As can be seen from each of those figures, a higher axial fuel speed will increase the equilibrium $k_{\text {eff }}$. This is due to the lower fuel residence time in higher axial fuel speed core making the core contain more fissile nuclides and finally resulting in a higher equilibrium $\mathrm{k}_{\text {eff }}$. A lower fuel residence time will also decrease the discharge burnup of the fuel. Fig. 7 shows that for a $4 \mathrm{~g} \mathrm{HM}$-loading with $17 \%$ U-235 enrichment and axial fuel speed of $0.8 \mathrm{~cm} /$ day a critical equilibrium core is not attained.

Both a lower HM-loading and a lower U-235 enrichment will decrease the equilibrium $k_{\text {eff }}$. The change of per-pebble HM-loading affects the balance between the fissile inventory and the moderation level. A lower HM-loading will decrease the fissile inventory but improve the moderation level, and vice-versa. In the $4 \mathrm{~g}$ and $5 \mathrm{~g}$ HM-loading designs, the effect of low fissile inventory is stronger than the moderation level improvement, hence the equilibrium $\mathrm{k}_{\text {eff }}$ decreases as HM-loading decreases. This effect is not always the case; the effect of the HM-loading to the equilibrium $\mathrm{k}_{\text {eff }}$ depend on whether the design is overor under-moderated [20]. The results show that the current design which achieves high burnup using $4 \mathrm{~g}$ and $5 \mathrm{~g} \mathrm{HM}$ loading is an over-moderated design. It can be understood that the design options to find the desired equilibrium $\mathrm{k}_{\mathrm{eff}}$ are to decrease the axial fuel speed, decrease per-pebble HMloading, and decrease fuel enrichment.

Calculation results of the power density profile of the equilibrium cores are shown in Figs. 8-10. The effects of different axial fuel speeds to the maximum power density are given in Fig. 8. It shows that a higher axial fuel speed is preferable for the safety aspect due to its low maximum power density. However, increasing the axial fuel speed also decreases the burnup of the core. Figure 9 shows that decreasing the per-pebble HMloading, which is preferable to increasing the burnup of the core, will also increase the maximum power density which is displeasing for the core design. The effects of different enrichments to the maximum power density are shown in Fig. 10. A higher fuel enrichment will decrease the maximum power density; however, as discussed earlier, it will also gives a higher equilibrium $\mathrm{k}_{\mathrm{eff}}$. These results show that the axial fuel speed, HMloading, and fuel enrichment need to be optimized to have an optimum burnup while keeping the maximum power density below the technical limit.

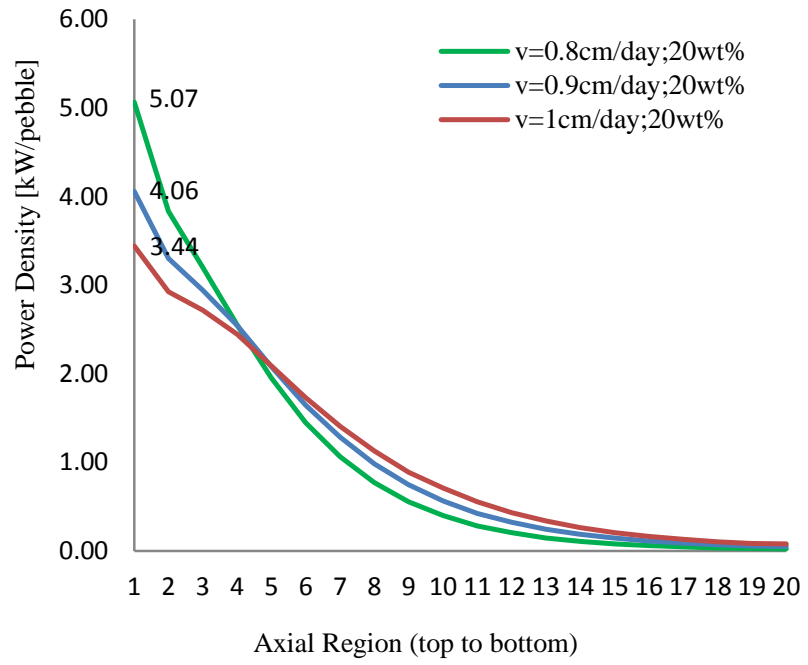

Fig. 8. Effect of different average axial speed to the maximum power density. (200 MWt, 20\%, 4 gHM/pebble)

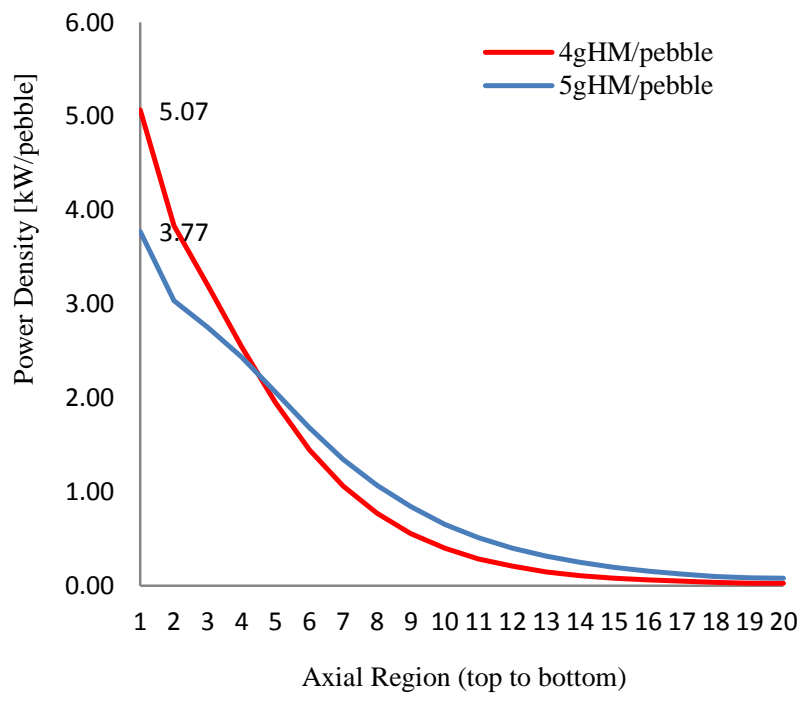

Fig. 9. Effect of different per-pebble HM-loadings to the axial power density profiles for $20 \% \mathrm{U}-235$ enrichment, $4 \mathrm{~g} \mathrm{HM} /$ pebble, at an average axial fuel speed of $0.8 \mathrm{~cm} /$ day.

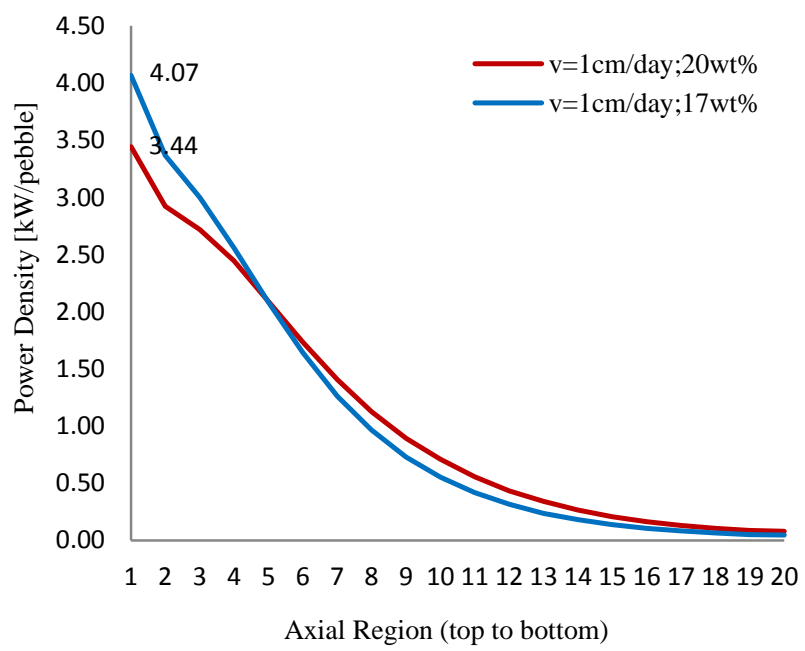

Fig. 10. Effect of different U-235 enrichments to the axial power density profiles for $4 \mathrm{~g} \mathrm{HM} /$ pebble, at an average axial fuel speed of 1 $\mathrm{cm} /$ day. 
The results of the optimization study of the axial fuel speed, HM-loading, and fuel enrichment to the burnup value and maximum power density are given in Fig. 11, while Fig. 12 shows the optimization of these parameters for burnup and equilibrium $k_{\text {eff. }}$ Both figures show the characteristics of OTTO cycle PBR optimization involving fuel enrichment, HM-loading, and axial fuel speed parameters. Based on the parametric survey results, for the $5 \mathrm{~g} \mathrm{HM} /$ pebble, a design with a fuel enrichment of $20 \%$ and an axial fuel speed of $0.8 \mathrm{~cm} /$ day fulfills the maximum power density limit and attains a burnup value of $131.1 \mathrm{MWd} / \mathrm{Kg}$ HM. The equilibrium $k_{\text {eff }}$ of this design is 1.15. For this design, increasing the axial fuel speed will further increase the equilibrium $\mathrm{k}_{\text {eff }}$, while decreasing the axial fuel speed will increase the maximum power density beyond the technical limit. A lower fuel enrichment of $17 \%$ decreases the equilibrium $\mathrm{k}_{\mathrm{eff}}$ to 1.08 ; however, the maximum power density increases to $4.3 \mathrm{~kW} /$ pebble. For the design with $4 \mathrm{~g} \mathrm{HM} /$ pebble, in general, the burnup is higher but the maximum power density also increases. A burnup of $145.7 \mathrm{MWd} / \mathrm{Kg}-\mathrm{HM}$ can be achieved with $4 \mathrm{~g} \mathrm{HM} /$ pebble and $20 \%$ enrichment while maintaining the maximum power density limit, however the equilibrium $\mathrm{k}_{\text {eff }}$ is 1.12 . Combining the desired criteria of optimum burnup, the maximum power density constrain, and the low equilibrium $\mathrm{k}_{\mathrm{eff}}$, the optimization study show that the design with $4 \mathrm{~g} \mathrm{HM} /$ pebble, $17 \%$ fuel enrichment, and an axial fuel speed of $1 \mathrm{~cm} /$ day is the optimum design. It attains a burnup value of $131.1 \mathrm{MWd} / \mathrm{Kg}-\mathrm{HM}$ with a maximum power density of $4.1 \mathrm{~kW} / \mathrm{cm}^{3}$ and an equilibrium $\mathrm{k}_{\text {eff }}$ of 1.07. The burnup of this optimized design is much higher than the $80 \mathrm{MWd} / \mathrm{Kg}-\mathrm{HM}$ burnup value of the reference HTR-MODUL design and the 100 MWt OTTO cycle PBR design by Teuchert et al. [9]. While the maximum power density of this design is kept below the technical limit to assure the integrity of the pebbles, a thermofluid analysis is needed in the next phase of this design study. Basically, the thermal load effect to the pebble due to this maximum power density can be reduced because this maximum power density occurred at the top part of the core which contains quite fresh pebbles and low temperature He coolant [5].

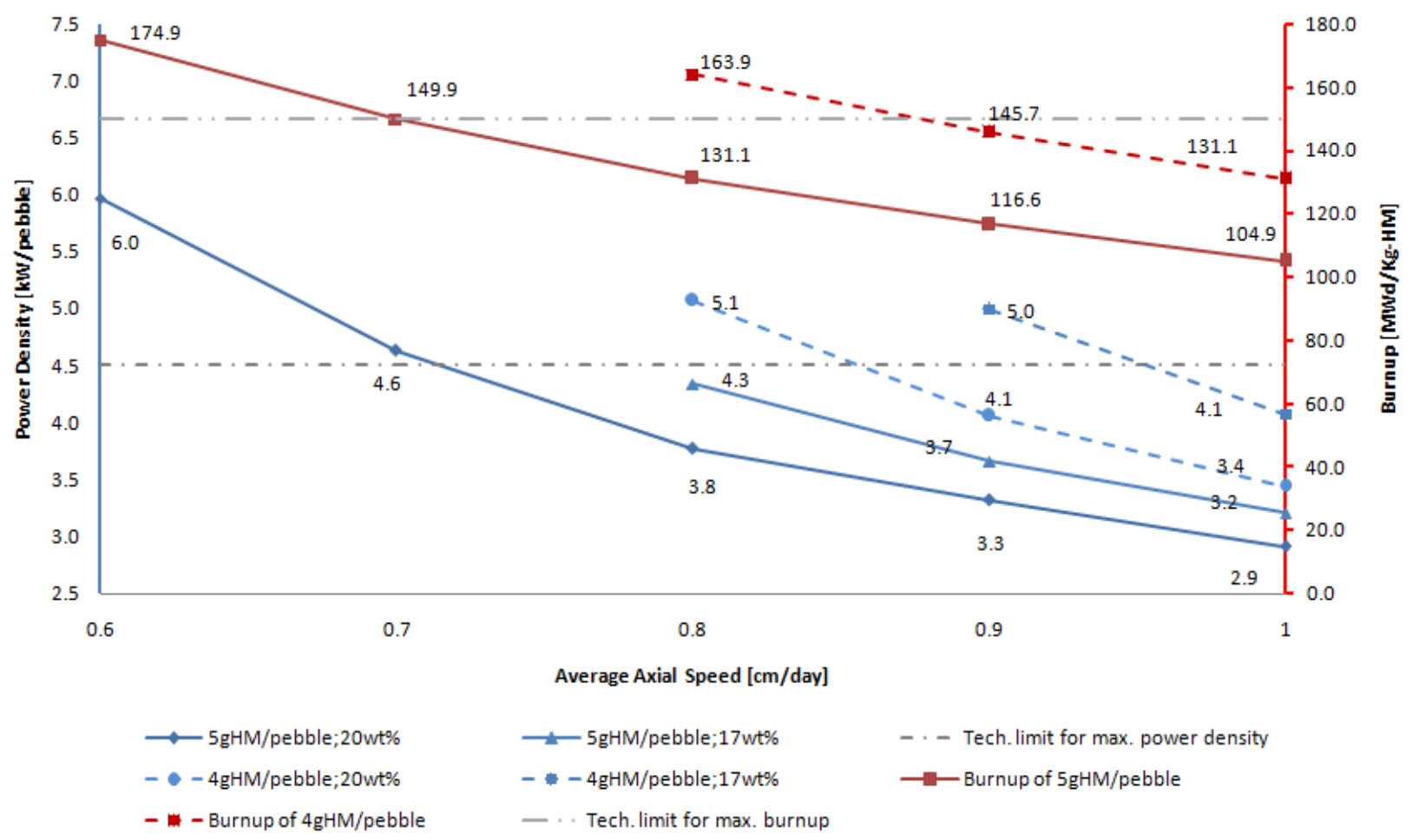

Fig. 11. Parametric survey results of average axial velocity, HM-loading, and U-235 enrichment to the maximum power density and burnup. 


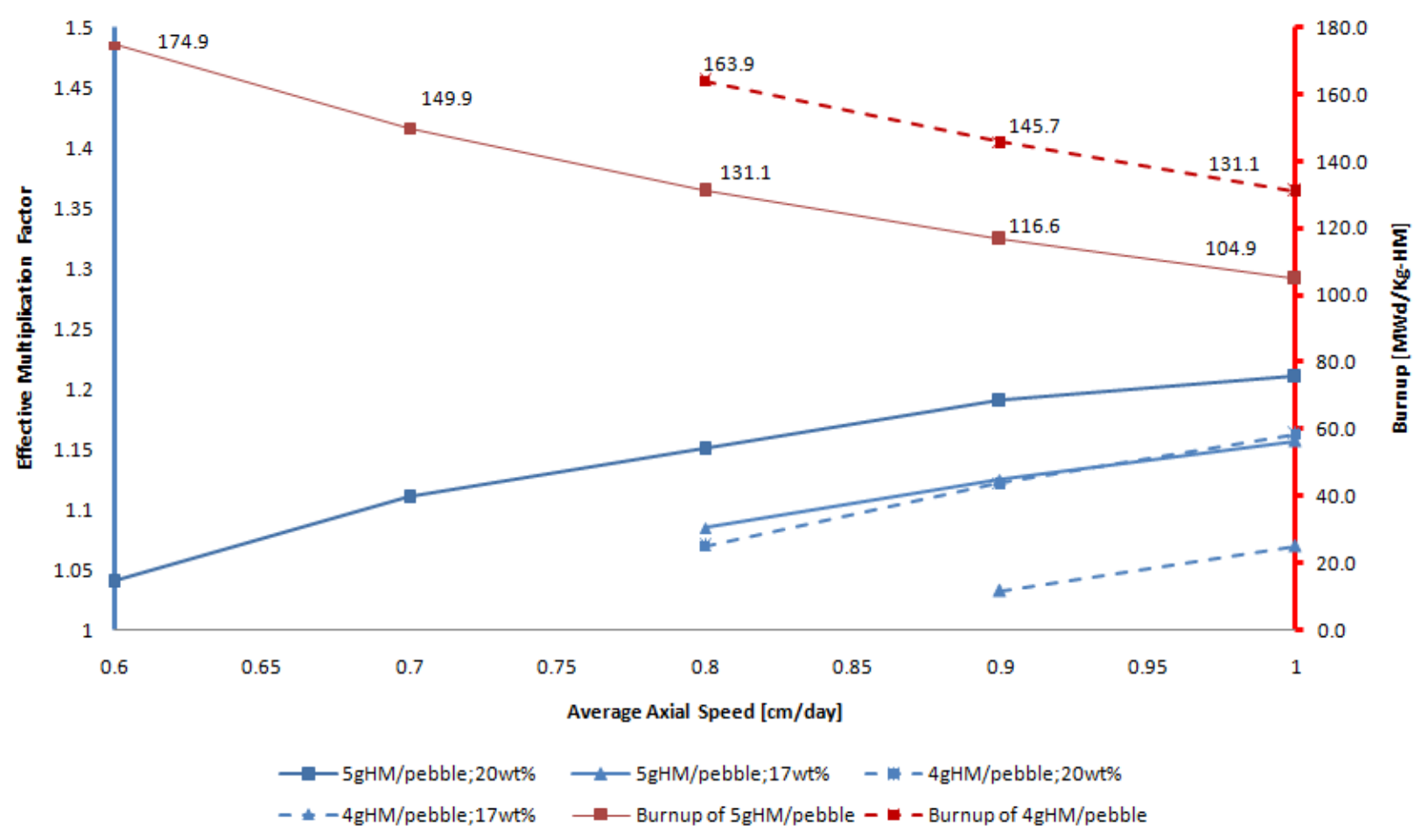

Fig. 12. Parametric survey results of average axial velocity, HM-loading, and U-235 enrichment to the equilibrium $\mathrm{k}_{\text {eff }}$ and burnup.

\section{CONCLUSION}

The preliminary neutronic design of a 200 MWt OTTO Cycle PBR had been performed. The design achieved a high burnup of 131.1 MWd/Kg-HM with a $17 \%$ U-235 enrichment and a loading of $4 \mathrm{~g}-\mathrm{HM} /$ pebble. The burnup improvement of this design is quite significant compared to the HTR-MODUL and the previously proposed OTTO-cycle PBR. The maximum power generation of the design is $4.1 \mathrm{~kW} /$ pebble which fulfills the criteria of lower than the technical limit of $4.5 \mathrm{~kW} /$ pebble. This optimized OTTO cycle PBR design is an interesting nuclear reactor design to be used for electricity and co-generation application in developing countries such as Indonesia, both due to the strong inherent safety of PBR design and, most particularly, due to its efficient nuclear fuel utilization and simplicity. Further studies which include initial core optimization and thermofluid aspect of this PBR design are some of the important agenda for the near future.

\section{ACKNOWLEDGMENT}

The authors would like to thank the Neutronic Group at the Center for Nuclear Reactor Technology and Safety of BATAN for the discussions on the design principles of PBR design .

\section{REFERENCES}

1. I. Keppler, Nucl. Eng. Des. 258 (2013) 102.

2. P.H. Liem, Ann. Nucl. Energy 23 (1996) 207.

3. Suwoto and Zuhair, Effect of latest nuclear cross section library on neutronic design calculation of RGTT200K core, Proceeding of $18^{\text {th }}$ National Seminar on Technology and Safety of NPP and Nuclear Facilities (2012) 502. (in Indonesian).

4. Zuhair, Suwoto and P.I. Yazid, Indonesian Journal of Nuclear Science and Technology 14 (2013) 65. (in Indonesian).

5. A. Bredimas, K. Kugeler and M.A. Futterer, Nucl. Eng. Des. 271 (2014) 193.

6. H.N. Tran, Prog. Nucl. Energy 60 (2012) 47.

7. F.J. Wols, J.L. Kloosterman, D. Lathouwers, et al., Ann. of Nucl. Energy 75 (2015) 542.

8. H.N. Tran, V.K. Hoang, Nucl. Eng. Des. 253 (2012) 269.

9. E. Teuchert, H. Gerwin and K.A. Haas, Simplification of the Pebble Bed HighTemperature Reactor, In: Potential of Small Nuclear Reactors for Future Clean and Safe Energy Sources, H. Sekimoto (Ed.), Elsevier Science Publishers B.V., Japan (1992). 
10. G.H. Lohnert, Nucl. Eng. Des. 121 (1990) 256.

11. D. Irwanto and T. Obara, Ann. of Nucl. Energy 60 (2013) 383.

12. T. Setiadipura and T. Obara, Ann. of Nucl. Energy 71 (2014) 313.

13. K. Okumura, T. Mori, M. Nakagawa, et al., J. Nucl. Sci. Tech. 37 (2000) 128.

14. H.C. Kim, S.H. Kim and J.K. Kim, Ann. of Nucl. Energy 38 (2011) 1877.

15. A. Abedi and N. Vosoughi, Nucl. Eng. Des. 253 (2012) 277.
16. V. Rintala, H. Suikkanen, J. Leppanen, et al., Ann. of Nucl. Energy 77 (2015) 233.

17. E. Bomboni, N. Cerullo and G. Lomonaco, Ann. of Nucl. Energy 40 (2012) 72.

18. D. Irwanto and T. Obara, J. Nucl. Sci. Tech. 48 (2011) 1385

19. K. Shibata, O. Iwamoto, T. Nakagawa, et al., J. Nucl. Sci. Technol. 48 (2011) 1.

20. T. Setiadipura, Study on optimization of start-up of OTTO cycle pebble bed reactors, $\mathrm{Ph} . \mathrm{D}$ Thesis, Tokyo Institute of Technology (2014). 